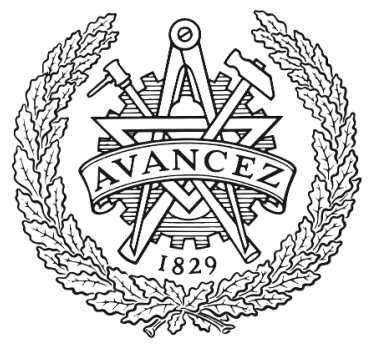

CHALMERS

UNIVERSITY OF TECHNOLOGY

\title{
Comparative Greenhouse Gas Footprinting of Online versus Traditional Shopping for Fast-Moving Consumer Goods: A Stochastic Approach
}

Downloaded from: https://research.chalmers.se, 2023-04-26 10:19 UTC

Citation for the original published paper (version of record):

Shahmohammadi, S., Steinmann, Z., Tambjerg, L. et al (2020). Comparative Greenhouse Gas Footprinting of Online versus Traditional Shopping for Fast-Moving

Consumer Goods: A Stochastic Approach. Environmental Science \& Technology, 54(6): 3499-3509. http://dx.doi.org/10.1021/acs.est.9b06252

N.B. When citing this work, cite the original published paper. 


\section{Comparative Greenhouse Gas Footprinting of Online versus Traditional Shopping for Fast-Moving Consumer Goods: A Stochastic Approach}

Sadegh Shahmohammadi,* Zoran J. N. Steinmann, Lau Tambjerg, Patricia van Loon, J. M. Henry King, and Mark A. J. Huijbregts

Cite This: Environ. Sci. Technol. 2020, 54, 3499-3509

Read Online

\section{ACCESS |}

W Metrics \& More

Article Recommendations

Supporting Information

ABSTRACT: Variability in consumer practices and choices is typically not addressed in comparisons of environmental impacts of traditional shopping and e-commerce. Here, we developed a stochastic model to quantify the variability in the greenhouse gas (GHG) footprints of product distribution and purchase of fast-moving consumer goods (FMCGs) via three prevalent retail channels in the United Kingdom (U.K.). We found that shopping via bricks and clicks (click and fulfillment via physical store delivery) most likely decreases the GHG footprints when substituting traditional shopping, while FMCGs purchased through pure players with parcel delivery often have higher GHG footprints compared to those purchased via traditional retail. The number of items purchased and the last-mile travel distance are the dominant contributors to the variability in the GHG footprints of all three retail channels. We further showed that substituting delivery vans with electric

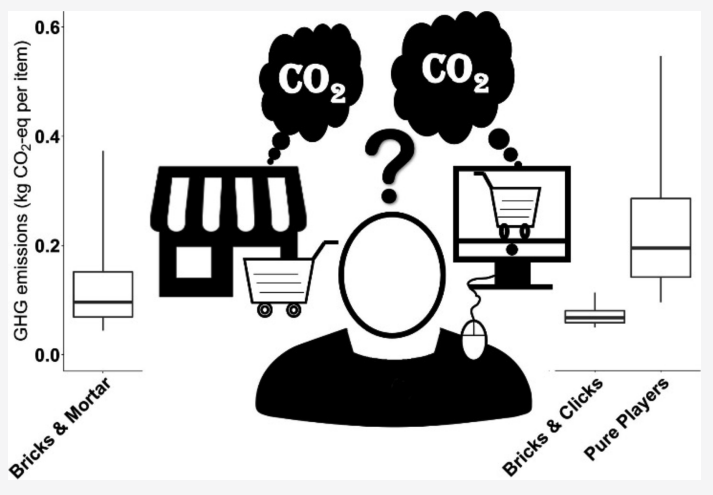
cargo bikes can lead to a GHG emission reduction of $26 \%$ via parcel delivery.

Finally, we showed the differences in the "last mile" GHG footprint of traditional shopping in the U.K. compared to three other countries (China, Netherlands, and the United States), which are primarily caused by the different shares of modes of transport (walking and by car, bus, and bike).

\section{INTRODUCTION}

Fast-moving consumer goods (FMCGs), such as personal care and homecare products, are typically defined as competitively low-priced products that sell quickly and are purchased frequently. ${ }^{1}$ FMCGs have traditionally been sold via physical retail stores (brick and mortar), but the share of sales via ecommerce channels is increasing. ${ }^{2}$ For example, the online value share of the FMCG market in China, the United Kingdom, and the United States in 2017 was 6.2, 7.5, and 1.5\% and is forecast to rise to 15,12 , and $8 \%$, respectively, by 2025 . $^{2}$ This shift in sales will affect the environmental impacts associated with the purchase of such products.

E-commerce covers a wide range of shopping models, but the two main types of e-commerce are the "store-based" model, often called bricks and clicks (e.g., online ordering and fulfillment via a physical shop or store), and "non-store-based" model, often called "pure play", typically conducted by ecommerce retailers. ${ }^{2,3}$ These two e-commerce models have different supply chain configurations (e.g., warehousing and logistics) and hence different GHG footprints. ${ }^{3}$ A number of studies suggest that e-commerce has a lower GHG footprint than that of traditional shopping, ${ }^{4-6}$ although one must be careful not to draw general conclusions given the complexity and diversity of the retail environment and consumer shopping practices. 3,7

The GHG emissions of product distribution and purchase (including collection and delivery to the home) of traditional retail and e-commerce are region-dependent and influenced by both supply chain configuration and consumer-related factors. The choice of the shopping channel is the first source of variability. Consumer density of the region influences the performance of all three retail channels. When an online channel is used, the delivery window, the timeframe that something needs to be delivered within, is shown as an important variable. ${ }^{8}$ The GHG footprints of parcel delivery calculated from the annual reports of some of the main parcel companies who perform pure players' delivery vary by a factor of 3 (0.4-1.2 kg CO $2 \mathrm{eq} /$ parcel).$^{9-13}$ When the brick-andmortar method is used, the mode of transport, distances traveled, number of products purchased, and fuel efficiency of vehicles are key variables. As an example, in the U.S.A., 95\% of

Received: October 16, 2019

Revised: January 25, 2020

Accepted: January 28, 2020

Published: February 26, 2020 


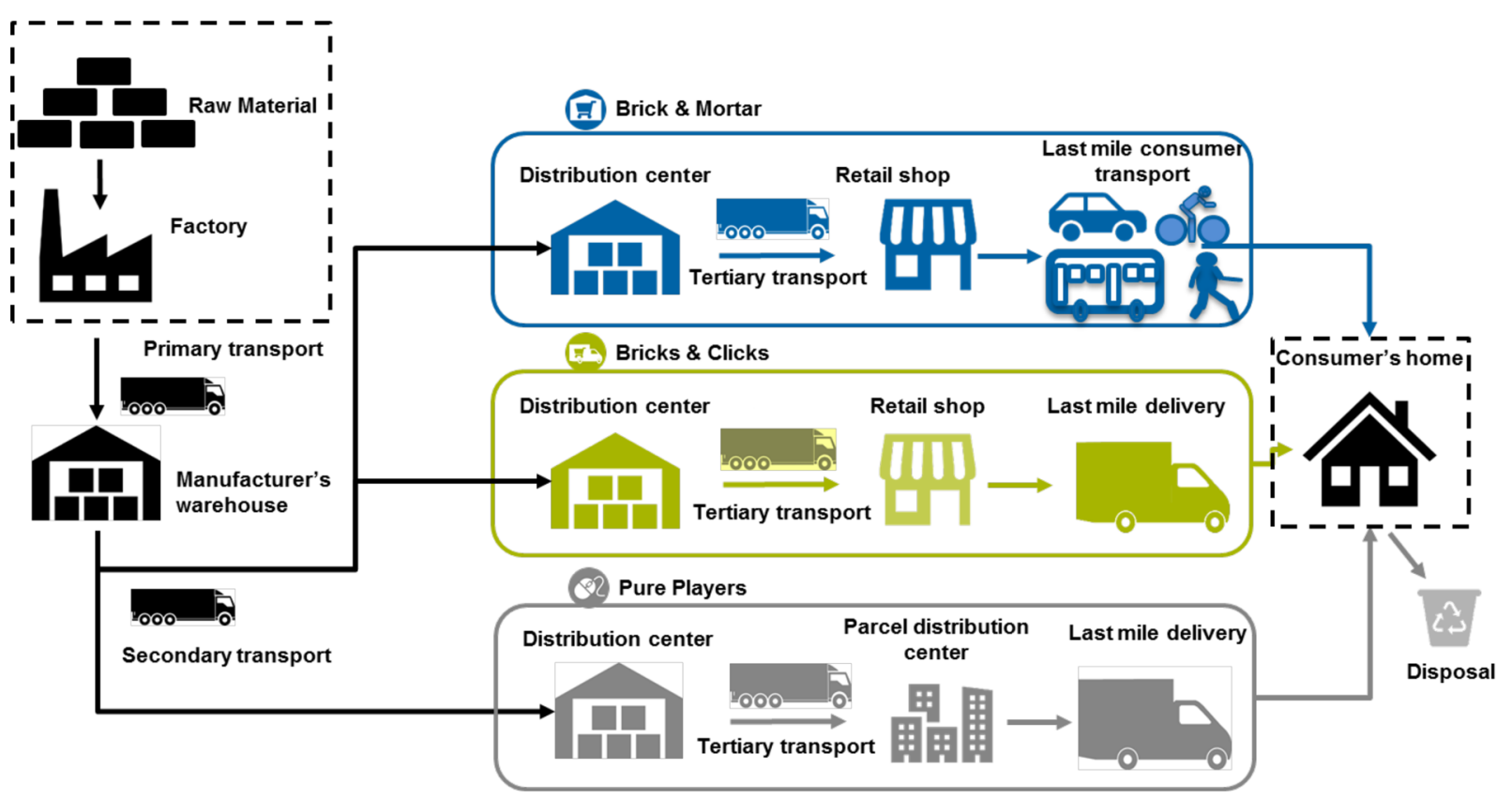

Figure 1. Scope of the study: U.K. market. Variables presented in the dashed box are excluded from this study. Only disposal of the delivery packaging for the pure-play channel is included in the model.

shopping trips are made by $\operatorname{car}^{14}$ compared to only $44 \%$ in the Netherlands. ${ }^{15}$ Depending on the functional unit, the type, number, size, mass, and price of products purchased through each retail channel could also be critical variables in the GHG footprint. For example, the GHG footprint of clothes purchased online can be very different from those purchased via brick and mortar as the return rate is much higher for online purchases. ${ }^{16}$ The basket size is also highly variable and mainly related to the living situation of the consumers. ${ }^{17}$ van Loon et al. ${ }^{3}$ showed that, when only a single FMCG item is purchased, the life-cycle GHG footprint of shopping through "pure players with parcel delivery networks" is around half that of shopping through brick and mortar (0.9 vs $2.04 \mathrm{~kg} \mathrm{CO} \mathrm{CO}_{2} \mathrm{eq} /$ item). At the same time, they also showed that life-cycle GHG emissions per item delivered via pure players can be much higher than those of traditional retailing when the actual number of products purchased through each channel is considered ( 0.81 vs $0.24 \mathrm{~kg} \mathrm{CO}$ eq/item).

Even though the way consumers perform their FMCG shopping is known to be highly variable both within and across countries, it is not typically quantified mainly due to a scarcity of specific data on consumer shopping practices. ${ }^{18}$ While deterministic models ignore a large range of differences in realworld activities, quantification of variability in the GHG footprints and calculation of the contribution of different variables to the overall variance provide a better understanding of the footprints and their key drivers. ${ }^{19}$ A stochastic model has two main advantages: (1) it enables us to probabilistically compare the GHG footprint of shopping through different retail channels, and (2) it enables us to quantify the contribution of each source of variability to the variability in the overall GHG footprints and consequently discover the opportunities for improvement.

The goal of this study was to systematically characterize, quantify, and compare the variability in the GHG footprint of product distribution and purchase of FMCG products purchased via three different retail channels, that is, "brick and mortar", "bricks and clicks", and "pure players", in the
United Kingdom. Monte Carlo simulation was used to propagate the variability throughout the supply chain. Since previous research has indicated that the last mile phase, that is, the transport of products from a transportation hub, such as a store or a warehouse, to consumers, has an important influence on the GHG footprint of FMCG items, ${ }^{2}$ we further investigated the role of consumer practices and choices on (1) the last mile footprints of brick and mortar in three other countries (Netherlands, the United States, and China) with different shopping behaviors and (2) the influence of using electric cargo bikes for the last mile footprints of pure players.

\section{MATERIALS AND METHODS}

2.1. Scope of the Study. 2.1.1. GHG Footprint of Product Distribution and Purchase of FMCG Products in the United Kingdom. The activities included in the GHG footprint of the FMCG products purchased in the U.K. from the point of manufacture to the consumer's home are summarized in Figure 1 and include transport, storage (e.g., warehousing, in store), and any delivery packaging activities. We used global warming potentials with a time horizon of 100 years to calculate the greenhouse gas footprints in $\mathrm{CO}_{2} \mathrm{eq}^{21}$ Three retail channels are considered, namely, (1) traditional retail (brick and mortar) and two e-commerce channels: (2) online retail and delivery from a store-based supplier (bricks and clicks) and (3) online retail and home parcel delivery from a non-store-based supplier (pure player).

The total GHG emissions associated with the purchase of one FMCG product via each retail channel were calculated by summing the GHG emissions from (i) upstream transport, that is, primary, secondary, and tertiary transport, (ii) energy use in warehousing/product storage, (iii) last mile transport, and (iv) transport packaging left with the consumer (for pure players only). In this study, primary transport is defined as the transport of products from the factory to the manufacturer's warehouse. Secondary transport is the transport of products from the manufacturer's warehouse to the retailer's distribution 
center, and tertiary transport is used when products are transported to either a retail shop (brick and mortar and bricks and clicks) or a parcel distribution center (pure players).

The allocation of GHG emissions to a single item was done in the following way:

(1) The GHG emissions due to storage and upstream transport of a single FMCG item were allocated based on the volume and weight of the product, respectively. We assumed that the same types of products are purchased through the different channels, and the weight and volume of the products were estimated using 2900 nonrefrigerated products supplied by the company Unilever.

(2) As suggested by Edwards et al., ${ }^{20}$ the GHG emissions from the last mile transport and transport packaging were allocated based on the basket size, that is, the number of products purchased through a specific channel. Passenger cars and delivery vans are often not full when they are used for the purpose of transporting FMCGs. This means that FMCGs' weight or volume is often not a limitation that affects the number of trips/ deliveries. $^{6}$

Excluded from the study are the following:

(1) All activities up to and including product manufacture, storage at home, and use and disposal of the product. These are assumed to be the same for all three retail channels.

(2) The GHG emissions associated with the construction of buildings, the employees for each retail channel, and IT (e.g., data centers and devices) used by retailers and consumers.

(3) Return and loss of products.

(4) Last-mile delivery packaging for both brick-and-mortar and bricks-and-clicks channels. Delivery packaging is considered to be negligible for these channels. ${ }^{3}$

2.1.2. Last-Mile GHG Emissions in China, Netherlands, the United Kingdom, and the United States for Brick and Mortar. In addition to the calculations performed for brick and mortar in the U.K., we gathered empirical data for three other countries with significantly different consumer traveling behaviors for the purpose of shopping, namely, China, Netherlands, and the United States to quantify the influence of inter-country behavioral variability in the last-mile transport.

2.1.3. Last-Mile GHG Emissions of Delivery Vans or Electric Cargo Bikes for Pure Players. The distance driven by the parcel companies' delivery vehicles can be divided into two parts:

(1) The so-called "stem mileage", that is, the distance between the depot of the parcel company and the delivery zone, and

(2) The "drop mileage", that is, the distance traveled after a delivery zone has been reached. ${ }^{21}$

While the stem mileage is almost always done by delivery vans, the drop mileage can also be performed by electric cargo bikes or tricycles rather than delivery vans. ${ }^{22}$ Although there are also other alternatives such as drones ${ }^{23}$ and robots, ${ }^{24}$ their application is quite limited. Parcel companies around the world are showing strong interest in cargo bikes, which could serve a considerable fraction of the last-mile deliveries in many areas of the world. ${ }^{25}$ The applications and environmental impacts of cargo bikes have been investigated in a number of recent studies $^{26-30}$ given that we also modeled a scenario in which cargo bikes were used for drop mileage.

2.2. GHG Footprint Equations. Equation 1 presents the formula that was used to calculate the total GHG emissions, that is, the GHG footprint, of shopping for FMCGs in the U.K.:

$$
\begin{aligned}
\mathrm{GHG}_{-} \mathrm{FP}_{i}= & \sum_{f} \mathrm{GHG} \_\mathrm{UT}_{f}+\sum_{f} \mathrm{GHG} \_\mathrm{S}_{f, i} \\
& +\mathrm{GHG} \_\mathrm{LM}_{i}+\mathrm{GHG} \mathrm{Pack}_{i}
\end{aligned}
$$

GHG $\mathrm{FP}_{i}$ is the GHG footprint associated with shopping through retail channel $i$ ( $\mathrm{kg} \mathrm{CO} \mathrm{CO}_{2}$ eq/item). GHG_UT $\mathrm{UT}_{f}$ is the GHG emissions associated with phase $f$ (primary, secondary, or tertiary) of upstream transport ( $\mathrm{kg} \mathrm{CO} \mathrm{CO}_{2} \mathrm{eq} /$ item). GHG_ $\mathrm{S}_{f, i}$ is the GHG emissions associated with phase $f$ (i.e., a warehouse, distribution center, or retail shop) of product storage for retail channel $i\left(\mathrm{~kg} \mathrm{CO} 2 \mathrm{eq} /\right.$ item). GHG_LM $\mathrm{LM}_{i}$ is the GHG emissions associated with the last-mile delivery phase of retail channel $i\left(\mathrm{~kg} \mathrm{CO} \mathrm{CO}_{2} \mathrm{eq} /\right.$ item). GHG_Pack ${ }_{i}$ is the GHG emissions associated with the delivery packaging for the retail channel $i(\mathrm{~kg} \mathrm{CO}$ eq/item).

2.2.1. Upstream Transport. Equation 2 was used to calculate the GHG emissions associated with each phase of upstream transport (i.e., primary, secondary, and tertiary transport). Then, the GHG UT's were summed to calculate the total GHG footprints related to upstream transport. The mode and distance of upstream transport were assumed to be identical for all retail channels considered.

$$
\text { GHG_UT }=\sum_{V}\left(C_{V} \times \mathrm{DT}_{V} \times \mathrm{GI}_{V} \times W_{\text {Prod }}\right)
$$

$V$ is the mode of transport. $C_{\mathrm{V}}$ is the probability of the type of transport mode $V$ (dimensionless). $\mathrm{DT}_{V}$ is the distance traveled by transport mode $V(\mathrm{~km}) . \mathrm{GI}_{V}$ is the GHG emission intensity of transport mode $V\left(\mathrm{~kg} \mathrm{CO} \mathrm{CO}_{2} \mathrm{eq} /(\mathrm{kg} \cdot \mathrm{km})\right) . W_{\text {Prod }}$ is the weight of the product $(\mathrm{kg} / \mathrm{item})$.

2.2.2. Product Storage in Retail Channels. Equation 3 was used to calculate the GHG emissions associated with storage of the FMCG product in the retail channels. GHG $S$ was separately calculated for the manufacturers' warehouses, distribution centers, parcel distribution centers, and retail shops. Then, the GHG emissions from the relevant phases $(f)$ to each retail channel $(i)$ were summed to calculate the total GHG footprint for product storage.

$$
\begin{aligned}
\mathrm{GHG}_{-} \mathrm{S}_{i}= & \left(E_{\mathrm{w}} \times \mathrm{GI}_{E}+G_{\mathrm{W}} \times \mathrm{GI}_{G}\right) \\
& \times \frac{\mathrm{T}_{\mathrm{W}} \times \mathrm{AF}_{w} \times V_{\text {Prod }}}{H_{\mathrm{w}}}
\end{aligned}
$$

$E_{\mathrm{W}}$ is the annual electricity use $\left(\mathrm{MJ} /\left(\mathrm{m}^{2} \cdot\right.\right.$ year $\left.)\right) . \mathrm{GI}_{\mathrm{E}}$ is the GHG emission intensity of electricity consumption from the U.K. grid $\left(\mathrm{kg} \mathrm{CO} \mathrm{CO}_{2} \mathrm{eq} / \mathrm{MJ}\right) . G_{\mathrm{W}}$ is the annual natural gas use $\left(\mathrm{MJ} /\left(\mathrm{m}^{2}\right.\right.$ year $\left.)\right) . \mathrm{GI}_{\mathrm{E}}$ is the $\mathrm{GHG}$ emission intensity of gas consumption $\left(\mathrm{kg} \mathrm{CO} \mathrm{CO}_{2} \mathrm{eq} / \mathrm{MJ}\right) . \mathrm{T}_{\mathrm{W}}$ is the storage time (year). $\mathrm{AF}_{\mathrm{W}}$ is the storage volume factor (fraction of the volume of the warehouse/store, which is dedicated to store the products) (dimensionless). $H_{\mathrm{W}}$ is the height of the warehouse/shelf stack (m). $V_{\text {Prod }}$ is the volume of the product $\left(\mathrm{m}^{3} /\right.$ item $)$.

2.2.3. Last-Mile Delivery. 2.2.3.1. Brick and Mortar. To quantify the GHG emissions associated with consumer travel to retail stores, we first chose the mode of travel based on the 
numbers provided in Table 2 and then assigned the corresponding variables using eq 4 .

$$
\text { GHG_LM }{ }_{\mathrm{BM}}=\frac{D_{\mathrm{BM}} \times 2 \times \mathrm{GI}_{\mathrm{TMode}}}{\mathrm{BS}}
$$

$D_{\mathrm{BM}}$ is the one-way travel distance $(\mathrm{km})$ (multiplied by 2 to account for the round-trip distance). $\mathrm{GI}_{\mathrm{TMode}}$ is the $\mathrm{GHG}$ intensity associated with the selected mode of transport $(\mathrm{kg}$ $\mathrm{CO}_{2} \mathrm{eq} / \mathrm{km}$ ). $\mathrm{BS}_{\mathrm{BM}}$ is the number of items per shopping trip in the brick-and-mortar channel (dimensionless).

2.2.3.2. Bricks and Clicks. We used eq 5 to quantify the lastmile GHG emissions associated with the delivery of products via bricks and clicks. Based on the information provided by van Loon et al., ${ }^{3}$ the failed delivery rate was considered to be negligible for bricks and clicks.

$$
G H G \_L M_{B C}=\frac{D_{B C} \times G I_{v e h}}{B S_{B C}}
$$

$D_{\mathrm{BC}}$ is the distance per delivery $(\mathrm{km}) . \mathrm{GI}_{\mathrm{veh}}$ is the GHG intensity of the delivery vehicle $(\mathrm{kg} \mathrm{CO} e \mathrm{eq} / \mathrm{km}) . \mathrm{BS}_{\mathrm{BC}}$ is the number of items per delivery in the bricks-and-clicks channel (dimensionless).

2.2.3.3. Pure Players. As shown in eq 6, we multiplied the total distance per delivery by the GHG emission intensity of delivery vehicles to quantify the GHG emissions associated with the last-mile delivery of the products. We allowed a maximum of one time of failed delivery in our model, when the consumer was not there to receive the parcel. Considering the information provided by Allen et al., ${ }^{16,31}$ a $14 \%$ chance of failed delivery was included for pure players. We then assumed that $50 \%$ of the failed deliveries are redelivered by the parcel company. For the other $50 \%$, we assumed that the parcel company leaves the parcel with a collection/delivery point (CDP) and the consumers would travel to the CDP to collect the parcels. We assumed that the consumers would walk to the CDP if the distance was not greater than $2 \mathrm{~km}$. For greater distances, we assumed that the parcels were collected by car.

$$
\begin{gathered}
\mathrm{GHG}_{-} \mathrm{LM}_{\mathrm{PP}}=\left[\left(\frac{2 \times \mathrm{SM}}{N_{\mathrm{D}}} \times \mathrm{GI}_{\mathrm{Veh}_{\mathrm{S}}}+\frac{\mathrm{DM}}{N_{\mathrm{D}}} \times \mathrm{GI}_{\left.\mathrm{Veh}_{\mathrm{D}}\right)}\right.\right. \\
\left.\times(1+F \times R)+F \times(1-R) \times D_{\mathrm{CDP}} \times \mathrm{GI}_{\mathrm{TC}}\right] / \mathrm{BS}_{\mathrm{PP}}
\end{gathered}
$$

$\mathrm{SM}$ is the one-way stem mileage $(\mathrm{km})$ (multiplied by 2 to account for a return trip). DM is the drop mileage $(\mathrm{km}) . N_{\mathrm{D}}$ is the number of parcels delivered (dimensionless). $\mathrm{GI}_{\mathrm{veh}} \mathrm{s} /$ $\mathrm{GI}_{\text {veh D }}$ is the GHG intensity of the delivery vehicle ( $\mathrm{kg}$ $\mathrm{CO}_{2} \mathrm{eq} / \mathrm{km}$ ) for stem mileage/drop mileage. $D_{\mathrm{CDP}}$ is the roundtrip distance to the nearest collection and delivery point (CDP) $(\mathrm{km}) . \mathrm{GI}_{\mathrm{TC}}$ is the GHG emission intensity of the travel to the nearest $\mathrm{CDP}(\mathrm{kg} \mathrm{CO} 2 \mathrm{eq} / \mathrm{km}) . F$ is a binary variable that equals 1 when the delivery is failed and equals 0 when the parcel is delivered to the consumer. $R$ is a binary variable that equals 1 when the parcel is re-delivered after a failed delivery and equals 0 when the parcel is delivered to a collection and delivery point after a failed delivery. $\mathrm{BS}_{\mathrm{PP}}$ is the number of items per delivery for pure players (dimensionless).

2.2.4. Last-Mile Delivery Packaging. We assumed that a corrugated cardboard box is used to pack the products, kraft paper is used to fill the void in the box, and the cardboard box and papers are sent to paper waste treatment after the parcel is opened. Then, we used eq 7 to calculate the GHG emissions related to the delivery packaging.

$$
\begin{aligned}
\mathrm{GHG}_{\text {Pack }, \mathrm{PP}}= & \left(\mathrm{GI}_{\mathrm{CB}}+\mathrm{GI}_{\text {Waste }}\right) \times \frac{V_{\text {Prod }} \times 1000 \times W_{\mathrm{CB}}}{S} \\
& +\left(\mathrm{GI}_{\mathrm{KF}}+\mathrm{GI}_{\text {Waste }}\right) \times V_{\text {Prod }} \times 1000 \\
& \times(1-S) \times W_{\mathrm{KF}}
\end{aligned}
$$

$\mathrm{GHG}_{\text {Pack, PP }}$ is the GHG emissions associated with the last mile packaging. $\mathrm{GI}_{\mathrm{CB}}$ is the $\mathrm{GHG}$ intensity of cardboard ( $\mathrm{kg}$ $\mathrm{CO}_{2} \mathrm{eq} / \mathrm{g}$ of cardboard). $\mathrm{GI}_{\text {Waste }}$ is the GHG emission intensity of paper waste treatment (in $\mathrm{kg} \mathrm{CO}$ eq/g of paper). $W_{\mathrm{CB}}$ is the cardboard used per liter of product $(\mathrm{g} / \mathrm{L}) . S$ is the box saturation (fraction of the box volume that is actually filled by products). $\mathrm{GI}_{\mathrm{KF}}$ is the $\mathrm{GHG}$ intensity of kraft paper ( $\mathrm{kg}$ $\mathrm{CO}_{2}$ eq/g of kraft paper). $W_{\mathrm{KF}}$ is the weight of the Kraft paper in grams used per liter of empty space ( $g$ of kraft paper/L of empty space). $V_{\text {Prod }}$ is the volume of product $\left(\mathrm{m}^{3} /\right.$ item $)$.

2.3. Data Sources. Finding sufficient data is a challenging and important step in developing stochastic models. We gathered raw data from various industry sources and national statistics and combined them with data available from the literature and LCA databases to be able to develop distributions for the input variables of our model (see Tables $1-3$ and Tables $S 1-S 5)$. We included variability in the (i)

Table 1. Variables Used in the Upstream Transport and Storage Phases

\begin{tabular}{llc}
\multicolumn{1}{c}{ phase } & \multicolumn{1}{c}{ variables } & ref \\
upstream transport & - product weight and volume & $33-35$ \\
& - probability of each mode of transport & \\
& - distance in each mode of transport & \\
storage & - electricity consumption & $36-42$ \\
& - heat consumption & \\
& - storage time & \\
& - storage volume factor \\
\hline
\end{tabular}

product weight and volume, (ii) upstream transport and storage of products, (iii) consumer choice of the retail channel, (iv) number of items purchased, (v) mode of travel, and (vi) GHG emission intensity of passenger cars.

Variable distributions were derived in the following order of preference:

(1) Where the probability distribution was provided by the reference, we used the given distribution.

(2) Where we had access to raw data, we derived the geometric mean and geometric standard deviation to define a lognormal distribution.

(3) When our access was limited to a minimum, a maximum, and the most likely value, we assumed that a BetaPERT distribution fits the data. The BetaPERT distribution gives more emphasis on the most likely value to match the shape of the normal distribution. ${ }^{32}$

(4) Where we only had a range, for example, for classes of transport distances, we used a uniform distribution.

For categorical variables, for example, the choice of the transport mode, we always implemented a custom distribution to select a category with a specified probability (see Section 2.4 for further information).

Table 1 provides an overview of the variables that are used in the upstream transport and the storage phases of our model. 
Table 2. Input Variables Related to the Last-Mile Phase of the Brick-and-Mortar Channel ${ }^{a}$

\begin{tabular}{|c|c|c|c|c|c|c|c|c|}
\hline \multirow[b]{2}{*}{ variable } & \multirow[b]{2}{*}{ country } & \multicolumn{4}{|c|}{ values } & \multirow[b]{2}{*}{ unit } & \multirow[b]{2}{*}{ distribution } & \multirow[b]{2}{*}{ ref } \\
\hline & & car & walk & bus & bike & & & \\
\hline \multirow[t]{4}{*}{ one-way distance $\left(D_{\mathrm{BM}}\right)^{b}$} & U.K. & $4.91,2.76$ & $1.21,1.85$ & $4.67,2.28$ & $1.87,2.19$ & \multirow[t]{4}{*}{$\mathrm{km}$} & lognormal & 45 \\
\hline & U.S.A. & $4.83,3.16$ & $0.40,2.35$ & $5.33,2.20$ & NA & & lognormal & 14 \\
\hline & NL & $3.51,3.61$ & $0.41,2.48$ & $6.14,2.90$ & $1.34,2.50$ & & lognormal & 15 \\
\hline & $\mathrm{CN}$ & $1.82,2.75$ & $0.6,1.86$ & $1.79,2.44$ & $0.9,2.20$ & & lognormal & 46 \\
\hline \multirow[t]{4}{*}{ mode of travel (TMode) $)^{b}$} & U.K. & 80 & 9 & 10 & 1 & \multirow[t]{4}{*}{$\%$} & custom & 45 \\
\hline & U.S.A. & 94 & 5 & 1 & 0 & & custom & 14 \\
\hline & NL & 44 & 17 & 7 & 31 & & custom & 15 \\
\hline & $\mathrm{CN}$ & 8 & 56 & 3 & 29 & & custom & 47 \\
\hline \multirow[t]{4}{*}{ GHG emission intensity $\left(\mathrm{GI}_{\mathrm{TMode}}\right)^{c}$} & U.K. & $0.12,1.27$ & 0 & $0.10,1.32$ & 0 & \multirow[t]{4}{*}{$\mathrm{kg} \mathrm{CO}{ }_{2} \mathrm{eq} / \mathrm{Km}$} & lognormal & 48,49 \\
\hline & U.S.A. & $0.18,1.30$ & 0 & $0.10,1.31$ & 0 & & lognormal & 48,49 \\
\hline & NL & $0.11,1.19$ & 0 & $0.11,1.20$ & 0 & & lognormal & 48,50 \\
\hline & $\mathrm{CN}$ & $0.15,1.18$ & 0 & $0.11,1.15$ & 0 & & lognormal & 48,49 \\
\hline shopping basket size $\left(\mathrm{BS}_{\mathrm{BM}}\right)^{d}$ & all & $1,30,70$ & $1,5,15$ & $1,10,20$ & $1,5,15$ & items & BetaPERT & 3,17 \\
\hline
\end{tabular}

${ }^{a}$ Where two numbers are reported, a lognormal distribution is defined by a geometric mean and geometric standard deviation. Where three numbers are reported, a BetaPERT distribution is used and the minimum, most likely, and maximum numbers are provided. ${ }^{b}$ Data for the mode of travel and the distances in the U.K., the U.S., and the Netherlands came from national travel studies. ${ }^{7,8,19}$ The data for China came from studies in Shanghai ${ }^{21}$ and Nanjing ${ }^{20}$ and are only considered to be representative of urban regions in China. See Section S3.1 of the Supporting Information for further details. ${ }^{c}$ See Section S3.1 of the Supporting Information for the calculation details. ${ }^{d}$ Rounded to the nearest integer. See Section S3.1 of the Supporting Information for further details.

Table 3. Input Variables Related to the Last-Mile Delivery of Bricks-and-Clicks and Pure-Play Channels ${ }^{a}$

\begin{tabular}{|c|c|c|c|c|c|}
\hline channel & variable & values & unit & distribution & ref \\
\hline \multirow[t]{3}{*}{ bricks and clicks } & distance per delivery $\left(D_{\mathrm{BS}}\right)$ & $2.1,4.3,7.3$ & $\mathrm{~km}$ & BetaPERT & 43 \\
\hline & number of items per delivery ${ }^{b}\left(\mathrm{BS}_{\mathrm{BC}}\right)$ & $5,45,100$ & & BetaPERT & 3 \\
\hline & GHG emission intensity of delivery vans $\left(\mathrm{GI}_{\mathrm{veh}}\right)^{c}$ & $0.26,1.26$ & $\mathrm{~kg} \mathrm{CO}{ }_{2} \mathrm{eq} / \mathrm{km}$ & lognormal & 51,52 \\
\hline \multirow[t]{6}{*}{ pure players' last-mile delivery } & stem mileage $(\mathrm{SM})^{d}$ & $17.87,2.15$ & $\mathrm{~km}$ & lognormal & 44 \\
\hline & drop mileage $\left(\mathrm{D}_{\mathrm{LM}-\mathrm{PP}}\right)$ & $11.9,45,96$ & $\mathrm{~km}$ & BetaPERT & $\begin{array}{l}4,16,20,31 \\
53-55\end{array}$ \\
\hline & number of deliveries $\left(N_{D}\right)$ & $32,100,168$ & parcels & BetaPERT & $4,16,31,53-57$ \\
\hline & number of items per delivery $\left(\mathrm{BS}_{\mathrm{PP}}\right)^{e}$ & $1,2,5$ & items & BetaPERT & $3,4,16,58$ \\
\hline & distance to the collection and delivery point $\left(D_{\mathrm{CDP}}\right)$ & $1,2,5$ & $\mathrm{~km}$ & BetaPERT & 53 \\
\hline & GHG emission intensity of delivery vans $\left(\mathrm{GI}_{\mathrm{van}}\right)$ & $0.26,1.26$ & $\mathrm{~kg} \mathrm{CO} \mathrm{Ce}_{2} / \mathrm{km}$ & lognormal & 51,52 \\
\hline \multirow{4}{*}{$\begin{array}{l}\text { pure players' transport } \\
\text { packaging }\end{array}$} & product volume $\left(V_{\text {prod }}\right)$ & $0.25,3.15$ & $\mathrm{~L}$ & lognormal & 33 \\
\hline & weight of corrugated cardboard $\left(W_{\mathrm{CB}}\right)$ & 12.5 & $\mathrm{~g} / \mathrm{L}$ & & 59 \\
\hline & $\begin{array}{l}\text { weight of kraft paper in grams used per liter of empty space } \\
\left(W_{\mathrm{KF}}\right)\end{array}$ & 0.033 & $\mathrm{~g} / \mathrm{L}$ & & 60 \\
\hline & box saturation $(S)$ & $10,50,90$ & $\%$ & BetaPERT & 61 \\
\hline
\end{tabular}

${ }^{a}$ Single numbers are modeled as a deterministic value. Where two numbers are reported, a lognormal distribution is assumed and geometric mean and geometric standard deviation are provided. Where three numbers are reported, a BetaPERT distribution is used and the minimum, most likely, and maximum numbers are provided. ${ }^{b}$ Rounded to the nearest integer. See Section S3.2 of the Supporting Information for further details. ${ }^{c}$ See Section S3.2 of the Supporting Information for further details. ${ }^{d}$ We multiplied this figure by 2 in our model to account for a round trip. See Section S3.3 of the Supporting Information for further details. ${ }^{e}$ Rounded to the nearest integer. See Section S3.3 of the Supporting Information for further details. ${ }^{f}$ Further information on the "end of life" phase of the delivery packaging is provided in Section S3.4 of the Supporting Information.

Note that the size and weight of FMCG products were specifically based on Unilever's portfolio of ambient stored products, that is, personal care products, homecare products, and food and refreshment products such as peanut butter and tea $\left.^{33}\right)$. The corresponding figures and assumptions are presented in Sections S1 and S2 of the Supporting Information.

The data and sources for the last-mile phase of the three retail channels are shown in Tables 2 (brick and mortar) and 3 (bricks and clicks and pure play). We used country-specific data for the last-mile travel phase in brick and mortar, and therefore the corresponding calculated GHG emissions are also country-specific. However, sufficient data to create a countryspecific distribution for the last-mile transport in the online channels was not available. The last mile transport in the online channels highly depends on the consumer density of the region where the products are delivered to. ${ }^{8}$ Therefore, we gathered data from different regions with potentially different consumer densities that influence the drop mileage for both bricks and clicks and pure play and logistical infrastructures related to parcel delivery that influences the stem mileage for pure play only. For bricks and clicks, we used data from Gonzalez-Feliu et al., ${ }^{43}$ which provided information for central urban, near-periphery, and far-periphery areas. For the pureplay channel, we estimated the distribution of stem mileage using information from Dablanc et al. ${ }^{44}$ who provided the distance between the warehouses to the center of gravity for 23 areas around the world covering a population density of between 70 and 5328 inhabitants $/ \mathrm{km}^{2}$. For the drop mileage, we found data from the literature for various regions with 


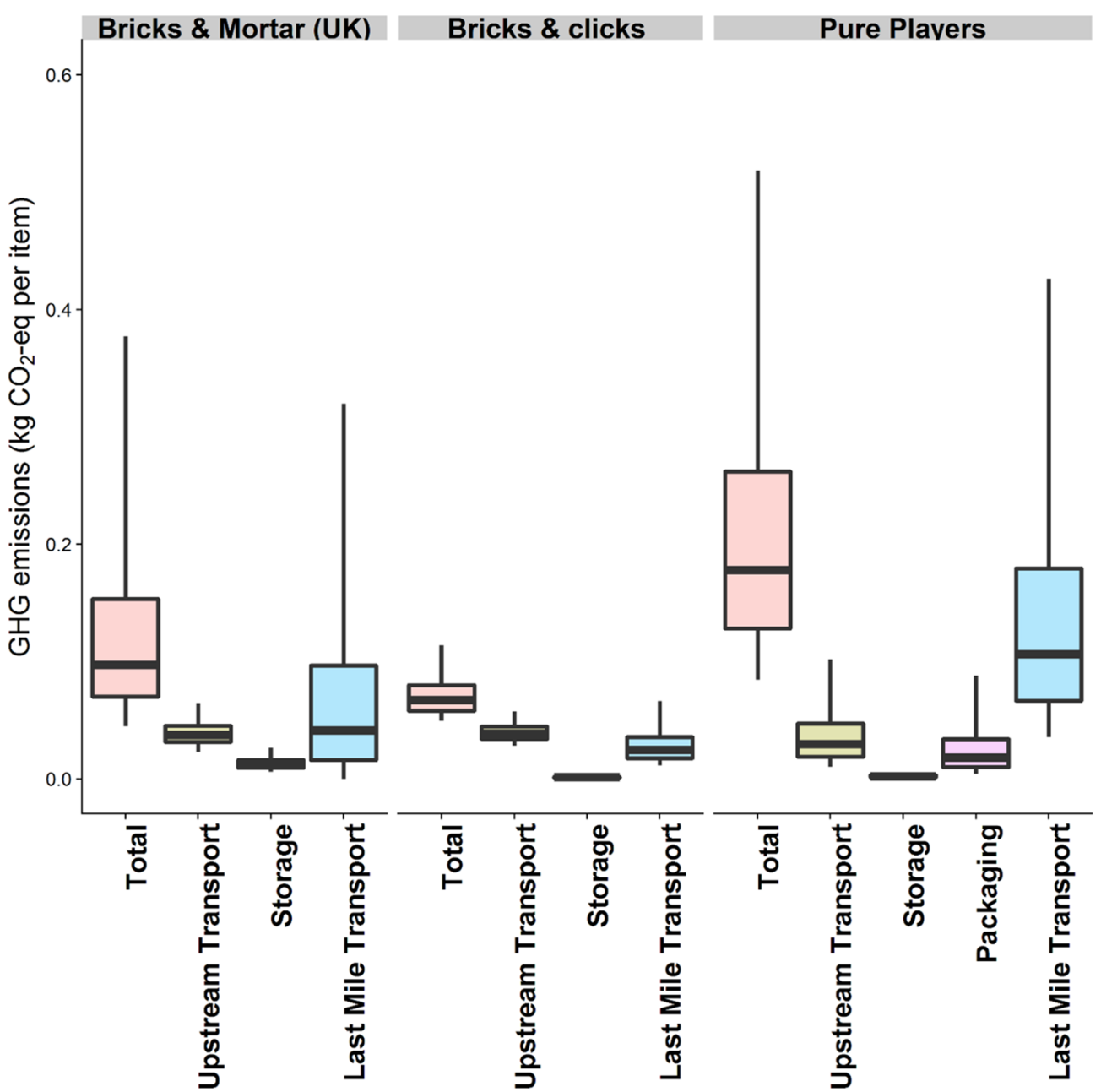

Figure 2. GHG footprint of different retail channels by phase in kg CO2eq/item. (Boxplots show the 5th, 25th, 50th, 75th, and 95th percentiles.)

various consumer densities in the U.K., the U.S., and Belgium (see Table 3) and used them to create the distribution. Therefore, our results for the last-mile travel are generic figures that can be used for the U.K. and also for other countries with a high variability in consumer density in different regions of the country. Further details of the assumptions related to the lastmile phase are presented in Section S3 of the Supporting Information. The GHG emission intensity of the different types of vehicles and materials that are used in this study is presented in Section S4 of the Supporting Information.

2.4. Model Simulation. To quantify the variability in the GHG footprints of a single FMCG purchased through each channel, a Monte Carlo simulation ${ }^{62}$ with 100,000 iterations was performed in $\mathrm{R}$ version $3.6 .1^{63}$ (the source code is provided in the Supporting Information). The simulation took 8.4 min on a PC with an Intel Core of i7-5600 CPU, 256 GB HDD, and 16 GB of RAM. In each iteration, a number was randomly selected from the distributions of the input variables, and eqs 1-7 were used to calculate the GHG footprints.

To include the role of travel modes in the brick and mortar channel and their associated distances in different countries, we first developed four discrete custom distributions (one for each country) each having probability values equal to the probability of the use of the different modes of travel in the four countries (see Table 2). Then, for each country and iteration, individual values were randomly selected for each parameter using its probability distribution.
To quantify the GHG emissions per item due to delivery packaging of pure players, we randomly sampled $n\left(=\mathrm{BS}_{\mathrm{PP}}\right.$ : the number of items per delivery) numbers from the generated distribution by eq 7 and summed them to estimate the total GHG emissions per delivery due to packaging. Then, we divided the GHG emissions per delivery by $\mathrm{BS}_{\mathrm{PP}}$.

To quantify the relative influence of the input parameters on the variability in the GHG footprints, we calculated the contribution to variance for all of the variables of the model following the procedure described by Shahmohammadi et al. ${ }^{64}$ For the categorical variables (e.g., mode of transport, truck type, and the use of ships), we first performed a multifactor analysis of variance (ANOVA). Then, we calculated the contribution to variance for each categorical variable by dividing the sum of squares of each variable by the total sum of squares. The remaining variability is explained by the continuous variables (distances, gas and electricity use by warehouses and retailers, etc.). For these variables, the squared Spearman's rank correlation coefficient for each input parameter of the GHG footprint of interest was divided by the sum of all squared rank correlation coefficients of the continuous input parameters.

\section{RESULTS}

3.1. GHG Footprint of Different Retail Channels. The GHG footprints per item for the different retail channels are shown in Figure 2. In $63 \%$ of the runs in our simulation, the 


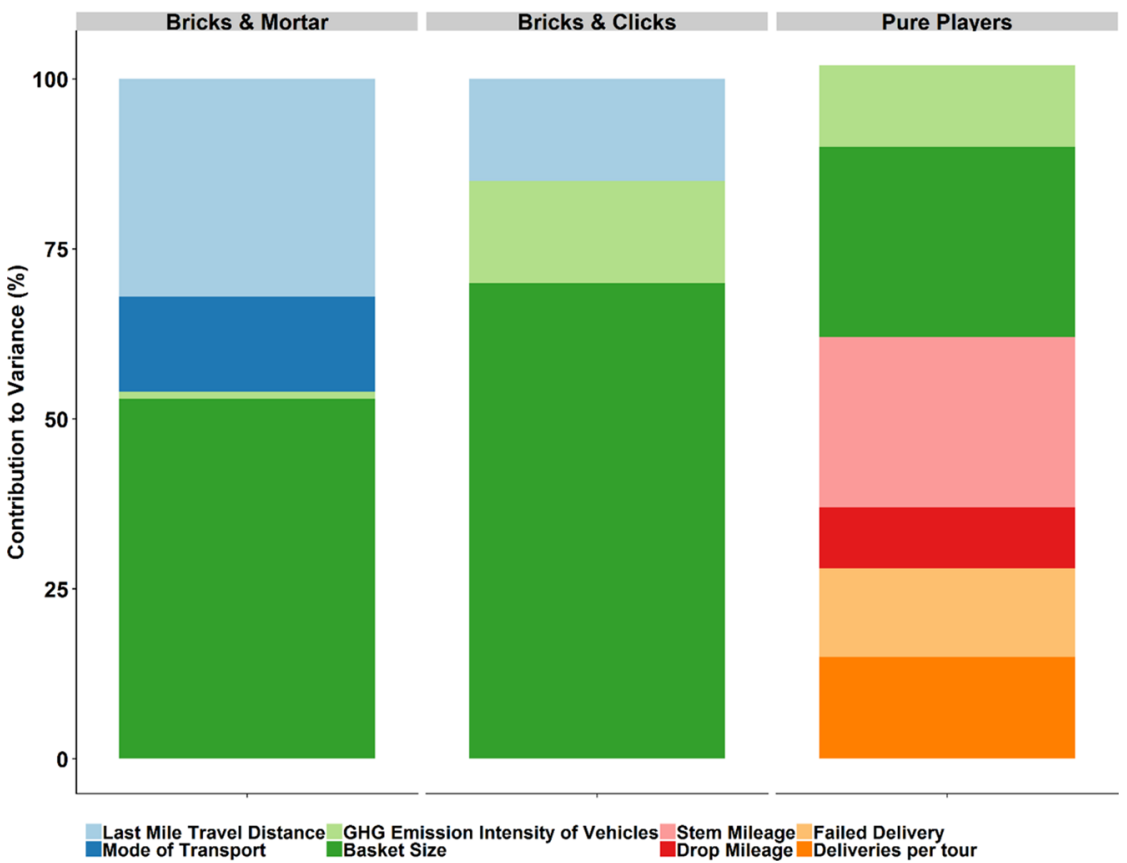

Figure 3. Contribution of input variables to the variance in the total GHG footprints.

total GHG footprints of brick and mortar (in the U.K.) are higher than those of bricks and clicks and lower than those of pure players in $81 \%$ of the simulation runs. The median total GHG emissions of $0.18 \mathrm{~kg} \mathrm{CO}$ eq/item (90\% interval $0.08-$ $0.52 \mathrm{~kg} \mathrm{CO}$ eq/item) delivered via the pure-play channel are approximately twice as high as the median total GHG emissions of traditional retailing $(0.10 \mathrm{~kg} \mathrm{CO}$ eq/item; $90 \%$ interval: $0.04-0.37 \mathrm{~kg} \mathrm{CO}$ eq/item) in the U.K. and 2-5 times greater than those of bricks and clicks $\left(0.07 \mathrm{~kg} \mathrm{CO}{ }_{2} \mathrm{eq} /\right.$ item; 90\% interval: $0.05-0.11 \mathrm{~kg} \mathrm{CO} 2 \mathrm{eq} /$ item). Upstream and last-mile transports account for the majority of the total GHG emissions, while the last-mile emissions show the highest variability.

The variability in GHG emissions associated with upstream transport is lowest for brick and mortar and bricks and clicks (0.03-0.06 $\mathrm{kg} \mathrm{CO} \mathrm{CO}_{2} \mathrm{eq} /$ item) and highest for pure players (0.01- $0.10 \mathrm{~kg} \mathrm{CO} 2 \mathrm{eq} /$ item). The GHG emissions of the lastmile packaging for pure players range between 0.003 and 0.09 $\mathrm{kg} \mathrm{CO}_{2}$ eq/item. The GHG emissions associated with the storage of products are small $\left(<0.01 \mathrm{~kg} \mathrm{CO} \mathrm{CO}_{2} \mathrm{eq}\right)$ in all cases. The last-mile transport has a median GHG footprint of $0.04 \mathrm{~kg}$ $\mathrm{CO}_{2}$ eq/item (90\% interval: $0-0.31 \mathrm{~kg} \mathrm{CO}$ eq/item) for brick and mortar, $0.02 \mathrm{~kg} \mathrm{CO}$ eq/item (90\% interval: $0.01-0.07 \mathrm{~kg}$ $\mathrm{CO}_{2} \mathrm{eq} /$ item) for bricks and clicks, and $0.11 \mathrm{~kg} \mathrm{CO} 2 \mathrm{eq} /$ item (90\% interval: $0.03-0.43 \mathrm{~kg} \mathrm{CO}$ eq/item) for the pure-play channel.

3.2. Contribution to Variance. Figure 3 shows that the basket size is the dominant source of variability in both brickand-mortar (in the U.K.) and bricks-and-clicks channels. For the pure-play channel where the number of items delivered varies between 1 and 5, the basket size contributes to $28 \%$ of the variance. The second major contributor to the variance is the last-mile travel distance with a share of $32 \%$ for brick and mortar, $15 \%$ for bricks and clicks, and 34\% (25\% from stem mileage and $9 \%$ from drop mileage) for pure players. While the GHG emission intensity of delivery vehicles used in the last mile accounts for 15 and $12 \%$ of the variance in the footprints of bricks and clicks and pure players, respectively, the GHG emission intensity of passenger cars only contributes to $1 \%$ of the variance in brick and mortar. Instead, the mode of transport has a considerable contribution to variance (14\%) for brick and mortar. The number of parcels delivered per delivery tour and the failed delivery rate account for 15 and $13 \%$ of the variance in the GHG footprint of pure players, respectively.

3.3. Differences in Last-Mile GHG Footprints between Countries (Brick and Mortar). Figure 4 shows that the last-

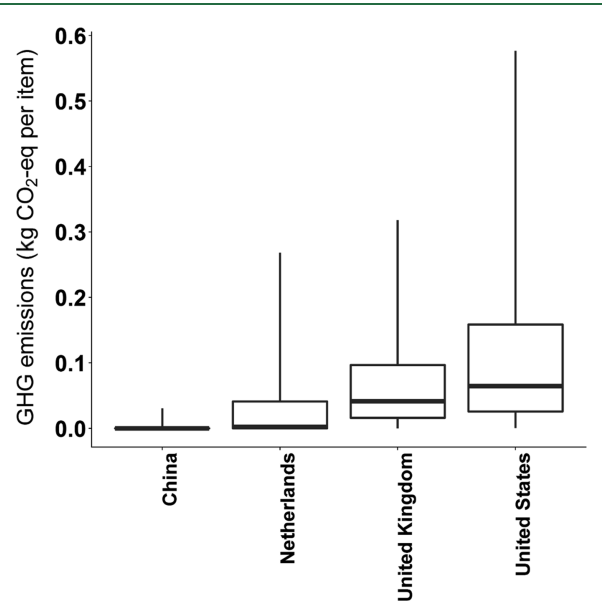

Figure 4. Last-mile GHG emissions (brick and mortar). The boxplot presents the 5th, 25th, 50th, 75th, and 95th percentiles.

mile GHG emissions in the brick-and-mortar channel vary from 0 in all countries (in cases where vehicles are not used) up to $0.03 \mathrm{~kg} \mathrm{CO}$ eq in China, $0.27 \mathrm{~kg} \mathrm{CO}_{2} \mathrm{eq}$ in the Netherlands, $0.31 \mathrm{~kg} \mathrm{CO}_{2}$ eq in the United Kingdom, and 0.56 $\mathrm{kg} \mathrm{CO}$ eq in the United States (95th percentiles). The median last-mile GHG emissions in China, Netherlands, the United Kingdom, and the United States are 0, 0.002, 0.041, and 0.065 $\mathrm{kg} \mathrm{CO}$ eq/item, respectively. The differences in the last-mile figures for brick and mortar are primarily caused by the 
different shares of each mode of transport used in different countries (see Table 2).

3.4. Use of Electric Cargo Bikes for Pure Players. Substituting delivery vans with electric cargo bikes leads to a GHG emission reduction of $0.02-0.11 \mathrm{~kg} \mathrm{CO}$ eq/item. The median GHG emissions associated with last-mile transport are $42 \%$ lower and the median footprints are $26 \%$ lower when fossil fuel vans are replaced by electric cargo bikes for the last phase of delivery, that is, the drop mileage.

\section{DISCUSSION}

4.1. Online versus Traditional Shopping. In this study, we compare the different retail channels from a climate-change impact perspective. Whether online shopping is better or worse than traditional shopping of FMCGs in terms of GHG emissions depends on the online retail channel and the consumer practices and choices in the region for which the comparison is made. Brick and mortar typically has a lower GHG footprint than pure-play retail. This finding contradicts the results of Edwards et al. ${ }^{4}$ who argued that online retailing can make a significant contribution to the development of a future low-carbon economy. They have, however, compared the GHG emissions per shopping event and did not consider the link between the retail channels and the basket size, which leads to a different conclusion than that of the current study. The GHG footprints calculated from the corporate sustainability reports of parcel companies such as GLS, ${ }^{9}$ UPS, ${ }^{10}$ DPD group, ${ }^{11}$ Hermes, ${ }^{12}$ and PostNL ${ }^{13}$ range between 0.4 and 1.2 $\mathrm{kg} \mathrm{CO}$ eq/parcel (which in our model includes $1-5$ items). These GHG footprints are larger than our average figure for the last-mile transport of pure players $(0.3 \mathrm{~kg} \mathrm{CO} 2 \mathrm{eq} /$ parcel $)$. This difference can be explained by the fact that not all of the deliveries by parcel companies are related to e-commerce. For example, $62 \%$ of the revenue gained by PostNL in 2017 was not related to e-commerce. ${ }^{13}$ For e-commerce, the last-mile distance (the sum of stem mileage and drop mileage) is rather short (see Table 3) as the parcel distribution centers are often relatively close to the areas where the parcels are being delivered to. In particular, FMCGs are often offered only relatively locally to prevent high transport costs on items with only a moderate margin. However, for deliveries that are not related to e-commerce, the distances could be much longer (e.g., when a parcel must be transported between two places that are far away or for international deliveries). In this study, we assumed that only vans are used for the last-mile delivery of the e-commerce channels, whereas the numbers reported by parcel delivery companies cover a wider range of services including air freight, which is not typically used for low-priced products like FMCGs. The GHG footprint related to air freight is relatively high $(1.1 \mathrm{~kg} \mathrm{CO} 2 \mathrm{eq} /(\mathrm{kg} \cdot \mathrm{km})),{ }^{65}$ and in $2018,59 \%$ of UPS' GHG footprints were related to airline fuels. ${ }^{66}$

Bricks and clicks has a lower median GHG footprint than brick and mortar in our study. This is in line with Wygonik et al., ${ }^{5}$ who observed $20-90 \%$ reductions in $\mathrm{CO}_{2}$ emissions when home delivery (bricks and clicks) substituted traditional grocery shopping in the U.S. However, for regions where consumers often walk or cycle to the shops, as in China, there is less or even no reduction in GHG emissions to be achieved by bricks and clicks.

4.2. Study Limitations. We selected two archetypes of ecommerce, that is, bricks and clicks and pure play, while other types of online shopping channels, such as pure play with its own van delivery (rather than through parcel delivery companies) and click and collect (where consumers order online and travel to a shop or collection point to retrieve their goods), are currently also employed. However, these new forms resemble the archetypes studied here with the supply chain of click and collect being similar to that of traditional retailing while pure players with van delivery is likely to be similar to bricks and clicks. ${ }^{3}$ Additionally, in some cases, products are returned by consumers, and this could add to the GHG emissions since additional transportation will be needed to return the products. Products could also be damaged or expire during transportation or in the stores. Previous research shows that return of products is typically higher in online channels, and unsold products are larger in traditional retailing, ${ }^{67}$ and the impacts of returns and losses could be significant for some products. ${ }^{67,68}$ Whether the overall effect of product returns and losses is lower for online shopping or traditional shopping is controversial. ${ }^{67,69,70}$ A number of studies argue that returns are negligible for FMCGs. ${ }^{3,71,72}$ However, we do not know whether the impacts of losses for FMCGs is higher in the online channels or in brick and mortar.

We also assumed that delivery packaging is negligible for brick and mortar and bricks and clicks because many consumers use reusable bags in the brick and mortar channel and returnable packaging is often used in the bricks and clicks channel. Besides, using data from the literature we found that including the use of plastic bags for the last-mile transport would have negligible influence on the GHG footprints of these channels (see Section S3.4 for more details). For the pure-play channel, even though both air-filled plastic and kraft paper are widely used to fill the void in the box, we based our calculations on the use of paper only. Given the small amount of paper or plastic used for this purpose, we do not expect to see significant changes in our results by adding air-filled plastic to our analysis (air-filled plastic weighs around $1 \mathrm{~g} /$ piece $^{73}$ ). The GHG emissions associated with information technology (IT) used by retailers and consumers were also assumed to be minor. Previous studies showed that the contribution of IT to GHG footprints of retail channels is less than $1 \% .^{3,18}$

Although great care was taken in gathering process-specific data for each retail channel, it was sometimes inevitable to make assumptions because of data limitations. Various sources of data are collected by both online and brick and mortar retailers. However, published empirical data on the type and number of products purchased are very limited, and therefore we had to make some assumptions regarding the basket size for each retail channel. Besides, for the last-mile delivery phase, we ignored the role of product weight and volume in GHG footprint allocation. Furthermore, we assumed that the same types of products are purchased through the different channels. However, while the top-selling FMCGs at supermarkets are food products, ${ }^{74,75}$ personal care and baby care products dominate the online basket. ${ }^{2}$ Buying bulkier products through online channels would lead to higher GHG emissions due to transportation, storage, and packaging. We further assumed that all upstream transport is the same for the three different channels even though the logistics of pure players could be different from that of brick and mortar and bricks and clicks, affecting GHG estimates related to secondary and tertiary transport. Systematically tracing the distribution steps for products through their entire supply chain could provide valuable information for better evaluation of the environmental impacts of different retail channels. However, as FMCGs are competitively low-priced products, detailed tracking and 
tracing of travel routes is not financially feasible using conventional technologies. Modern technologies such as a blockchain could potentially enable this level of traceability for a wide range of FMCGs in the near future. ${ }^{76-78}$

4.3. GHG Reduction Potential. Our results showed large variability in the GHG footprints of pure players and the GHG footprints of brick and mortar when vehicles are used for shopping. Consumers who shop traditionally (i.e., via brick and mortar) could reduce their GHG footprints by applying trip chaining (when the shopping trip is part of a larger trip, e.g., shopping when returning home from work) and by using cleaner modes of transport.

Pure players could reduce their last-mile footprints by switching from delivery vans to electric cargo bikes and also reducing the failed delivery rate. Another option for pure players to reduce their GHG footprints is to locate warehouses closer to their customers in order to decrease the stem mileage. However, Dablanc et al. ${ }^{44}$ studied the logistics sprawl in 25 metropolitan areas of the world and found that the average distance of warehouses to their barycenter (center of gravity) is increasing by a rate of $0.31 \mathrm{~km} /$ year. Pure players offer a huge range of products to consumers. However, these products are often not stored in one place, and therefore multiple deliveries might be required to fulfill an order when several products are purchased. Therefore, consumers could reduce the GHG footprints of their online purchase by purchasing multiple products from the same supplier and by choosing to bundle items rather than send each item as soon as it is ready. Consumers can also reduce the environmental impacts of their online shopping by foregoing fast delivery as it affects the routing efficiency. ${ }^{56}$ Nonetheless, Barr ${ }^{79}$ and Utter ${ }^{80}$ argue that consumers value the convenience that fast delivery offers and are unlikely to forego it. Indeed, consumers buy more products online when same-day delivery is available, and they are highly willing to pay for it. $^{81}$

The majority of online orders are found to substitute frequent trips to a grocery store and do not substitute the infrequent trips to purchase items for occasional events. ${ }^{44}$ Hiselius et al. ${ }^{82}$ argued that consumers who frequently shop online make the same total number of trips to shops as consumers who do not. Our results show that online purchasing of FMCGs via bricks and clicks most likely reduces the GHG footprints in regions where personal vehicles are often used for traditional shopping (e.g., the U.S.). However, online shopping of FMCGs could increase emissions in the regions where people often walk or cycle to the shops (e.g., China and the Netherlands), even when substituting rather than adding to the number of shopping trips. When online shopping does not substitute traditional shopping, GHG emissions associated with individuals' overall shopping activity will likely increase. This is exacerbated when online shopping is fulfilled by the rapidly growing pure players since these have the highest footprints per item delivered and barely substitute the consumer trips to supermarkets. ${ }^{3}$

\section{ASSOCIATED CONTENT}

\section{(s) Supporting Information}

The Supporting Information is available free of charge at https://pubs.acs.org/doi/10.1021/acs.est.9b06252.

Data tables, additional information on the assumptions of the study (PDF)
The $\mathrm{R}$ code of the model developed for the study (TXT)

\section{AUTHOR INFORMATION}

\section{Corresponding Author}

Sadegh Shahmohammadi - Department of Environmental Science, Institute for Water and Wetland Research, Faculty of Science, Radboud University Nijmegen, 6525 AJ Nijmegen, Netherlands; Environmental Modeling, Sensing and Analysis, TNO, 3584 CB Utrecht, Netherlands; ○ orcid.org/00000002-5818-9913; Email: sadegh_shahmohammadi@ yahoo.com

\section{Authors}

Zoran J. N. Steinmann - Department of Environmental Science, Institute for Water and Wetland Research, Faculty of Science, Radboud University Nijmegen, 6525 AJ Nijmegen, Netherlands; Department Of Environmental Sciences, Wageningen University \& Research, 6708PB Wageningen, Netherlands; 이이.org/ 0000-0001-8606-917X

Lau Tambjerg - Unilever Safety and Environmental Assurance Centre, Colworth Science Park, Bedford MK44 1LQ, United Kingdom

Patricia van Loon - Chalmers Industriteknik, 41258 Göteborg, Sweden

J. M. Henry King - Unilever Safety and Environmental Assurance Centre, Colworth Science Park, Bedford MK44 1LQ, United Kingdom

Mark A. J. Huijbregts - Department of Environmental Science, Institute for Water and Wetland Research, Faculty of Science, Radboud University Nijmegen, 6525 AJ Nijmegen, Netherlands

Complete contact information is available at:

https://pubs.acs.org/10.1021/acs.est.9b06252

\section{Notes}

The authors declare no competing financial interest.

\section{ACKNOWLEDGMENTS}

This project has received funding from the European Union's Horizon 2020 research and innovation program under the Marie Sklodowska-Curie grant agreement no. 641459 (RELIEF).

\section{REFERENCES}

(1) Kenton, W. Fast-Moving Consumer Goods (FMCG). 2019. https://www.investopedia.com/terms/f/fastmoving-consumer-goodsfmcg.asp.

(2) KANTAR Worldpanel THE FUTURE OF E-COMMERCE IN FMCG; KANTAR Worldpanel: November 2017.

(3) van Loon, P.; Deketele, L.; Dewaele, J.; McKinnon, A.; Rutherford, C. A comparative analysis of carbon emissions from online retailing of fast moving consumer goods. J. Cleaner Prod. 2015, 106, 478-486.

(4) Edwards, J. B.; McKinnon, A. C. Shopping trip or home delivery: which has the smaller carbon footprint? Logistics and transport focus 2009, 20.

(5) Wygonik, E.; Goodchild, A. Evaluating the efficacy of shared-use vehicles for reducing greenhouse gas emissions: a U.S. case study of grocery delivery. In Journal of the Transportation Research Forum; 2012.

(6) Siikavirta, H.; Punakivi, M.; Kärkkäinen, M.; Linnanen, L. Effects of E-Commerce on Greenhouse Gas Emissions: A Case Study of Grocery Home Delivery in Finland. J. Ind. Ecol. 2002, 6, 83-97. 
(7) Tiwari, S.; Singh, P. E-commerce: prospect or threat for environment. Int. J. Environ. Sci. Dev. 2011, 2, 211.

(8) Boyer, K. K.; Prud'homme, A. M.; Chung, W. The last mile challenge: evaluating the effects of customer density and delivery window patterns. J. Bus. Logist. 2009, 30, 185-201.

(9) GLS 3rd Sustainability Report 2016/2017; 2018.

(10) UPS UPS 2017 Corporate Sustainability Progress Report; 2018.

(11) DPDgroup Corporate Social Responsibility Report 2017; 2018.

(12) Hermes Sustainability Report 2015; 2016.

(13) PostNL Annual Report 2017: Accelerating transformation.

(14) U.S. Department of Transportation National Household Travel Survey. In Federal Highway Administration, Ed. 2017.

(15) Hoogendoorn-Lanser, S.; Schaap, N. T. W.; OldeKalter, M.-J. The Netherlands Mobility Panel: An innovative design approach for web-based longitudinal travel data collection. Transp. Res. Procedia 2015, 11, 311-329.

(16) Allen, J.; Piecyk, M.; Piotrowska, M.; McLeod, F.; Cherrett, T.; Ghali, K.; Nguyen, T.; Bektas, T.; Bates, O.; Friday, A.; Wise, S.; Austwick, M. Understanding the impact of e-commerce on last-mile light goods vehicle activity in urban areas: The case of London. Transp. Res. Part D: Transp. Environ. 2018, 61, 325-338.

(17) Market Track Driving Shopper Behavior in Grocery; 2014.

(18) Weber, C. L.; Hendrickson, C. T.; Matthews, H. S.; Nagengast, A.; Nealer, R.; Jaramillo, P. Life cycle comparison of traditional retail and e-commerce logistics for electronic products: A case study of buy. com. In Sustainable Systems and Technology, 2009. ISSST'09 IEEE International Symposium; IEEE: 2009; pp 1-6.

(19) di Sorrentino, E. P.; Woelbert, E.; Sala, S. Consumers and their behavior: state of the art in behavioral science supporting use phase modeling in LCA and ecodesign. Int. J. Life Cycle Assess. 2016, 21, 237-251.

(20) Edwards, J. B.; McKinnon, A. C.; Cullinane, S. L. Comparative analysis of the carbon footprints of conventional and online retailing: A "last mile" perspective. Int. J. Phys. Distrib. Logist. Manage. 2010, 40, $103-123$.

(21) Rushton, A.; Croucher, P.; Baker, P. The handbook of logistics and distribution management: Understanding the supply chain; Kogan Page Publishers: 2014.

(22) Jingzhu, L. Electric 3-wheelers in urban delivery in China and Germany - a bumpy road ahead? https://www.sustainabletransport. org/archives/5826, 18 April 2018.

(23) Goodchild, A.; Toy, J. Delivery by drone: An evaluation of unmanned aerial vehicle technology in reducing $\mathrm{CO}_{2}$ emissions in the delivery service industry. Transp. Res. Part D: Transp. Environ. 2018, $61,58-67$.

(24) Field, M. World's first robot delivery service launched in Milton Keynes. In The Telegraph: 2018.

(25) Reid, C. Cargobikes Not Drones Are The Future For Urban Deliveries. Forbes 2018.

(26) Gruber, J.; Kihm, A.; Lenz, B. A new vehicle for urban freight? An ex-ante evaluation of electric cargo bikes in courier services. Res. Transp. Bus. Manage. 2014, 11, 53-62.

(27) Nocerino, R.; Colorni, A.; Lia, F.; Luè, A. E-bikes and Escooters for smart logistics: environmental and economic sustainability in pro-E-bike Italian pilots. Transp. Res. Procedia 2016, 14, $2362-2371$.

(28) Sheth, M.; Butrina, P.; Goodchild, A.; McCormack, E. Measuring delivery route cost trade-offs between electric-assist cargo bicycles and delivery trucks in dense urban areas. Eur. Transp. Res. Rev. 2019, 11, 11.

(29) Saenz, J.; Figliozzi, M.; Faulin, J. Assessment of the Carbon Footprint Reductions of Tricycle Logistics Services. Transp. Res. Rec. 2016, 2570, 48-56.

(30) Arnold, F.; Cardenas, I.; Sörensen, K.; Dewulf, W. Simulation of B2C e-commerce distribution in Antwerp using cargo bikes and delivery points. Eur. Transp. Res. Rev. 2018, 10, 2.

(31) Allen, J.; Piecyk, M.; Piotrowska, M. An analysis of the parcels market and parcel carriers' operations in the UK. Freight Traffic Control 2016, 2050.
(32) Huizer, D.; Oldenkamp, R.; Ragas, A. M. J.; van Rooij, J. G. M.; Huijbregts, M. A. J. Separating uncertainty and physiological variability in human PBPK modelling: the example of 2-propanol and its metabolite acetone. Toxicol. Lett. 2012, 214, 154-165.

(33) Unilever, Weight and Volume of Products, 2015.

(34) Unilever, Transportation of Products in the UK and Ireland, 2017.

(35) Department for Transport, Road Fright Statistics: Table RFS0117, 2016.

(36) Unilever, Energy use of warehousing. Date of access: 15 Jan 2018.

(37) United States Census Bureau, Annual Retail Trade Survey, 2016.

(38) European Commission PEFCR Guidance document, - Guidance for the development of Product Environmental Footprint Category Rules (PEFCRs); 2017.

(39) Golsteijn, L.; Lessard, L.; Campion, J.-F.; Capelli, A.; D’Enfert, V.; King, H.; Kremer, J.; Krugman, M.; Orliac, H.; Furnemont, S. R.; Schuh, W.; Stalmans, M.; O’Hanlon, N. W.; Coroama, M. Developing Product Environmental Footprint Category Rules (PEFCR) for shampoos: The basis for comparable life cycle assessment. Integr. Environ. Assess. Manage. 2018, 14, 649-659.

(40) Fichtinger, J.; Ries, J. M.; Grosse, E. H.; Baker, P. Assessing the environmental impact of integrated inventory and warehouse management. Int. J. Prod. Econ. 2015, 170, 717-729.

(41) EIA, Commercial Buildings Energy Consumption Survey (CBECS), 2012.

(42) Stone, S. How to Measure and Improve Industrial Storage Space Efficiency, http://www.cisco-eagle.com/blog/2014/08/18/ how-to-measure-and-improve-industrial-storage-space-efficiency/, 18 Aug 2014.

(43) Gonzalez-Feliu, J.; Ambrosini, C.; Routhier, J.-L. New trends on urban goods movement: modelling and simulation of e-commerce distribution. European Transport 2012, 50, 23.

(44) Dablanc, L.; Liu, Z.; Koning, M.; Klauenberg, J.; de Oliveira, L. K.; Blanquart, C.; Combes, F.; Coulombel, N.; Gardrat, M.; Heitz, A. Observatory of Strategic Developments Impacting Urban Logistics (2017 version); IFSTTAR-Institut Français des Sciences et Technologies des Transports: 2017.

(45) Department for Transport, National Travel Survey, 2016.

(46) Feng, J.; Dijst, M.; Wissink, B.; Prillwitz, J. Changing travel behaviour in urban China: Evidence from Nanjing 2008-2011. Transp. Policy 2017, 53, 1-10.

(47) Wang, W. Comparing the Energy Consumption of Logistics Chains in Traditional Retailing and E-commerce for Popular Products in the Context of China. The ANU Undergraduate Research Journal 2014, 5, 243-267.

(48) Wernet, G.; Bauer, C.; Steubing, B.; Reinhard, J.; Moreno-Ruiz, E.; Weidema, B. The ecoinvent database version 3 (part I): overview and methodology. Int. J. Life Cycle Assess. 2016, 21, 1218-1230.

(49) Mercure, J.-F.; Lam, A. The effectiveness of policy on consumer choices for private road passenger transport emissions reductions in six major economies. Environ. Res. Lett. 2015, 10, No. 064008.

(50) European Environmental Agency Monitoring of CO2 emissions from passenger cars - Data 2017 - Final data; 2017.

(51) National Renewable Energy Laboratory U.S. Life Cycle Inventory Database; 2012.

(52) Network for Transport Measures Vehicle type characteristics and default load factors; 2015.

(53) McLeod, F. N.; Cherrett, T. J. Quantifying the environmental benefits of collection/delivery points. OR Insight 2009, 22, 127-139.

(54) Brown, J. R.; Guiffrida, A. L. Carbon emissions comparison of last mile delivery versus customer pickup. Int. J. Logist. Res. Appl. 2014, 17, 503-521.

(55) Arnold, F. Efficient heuristics for routing and integrated logistics; University of Antwerp: 2018.

(56) Gevaers, R.; Van de Voorde, E.; Vanelslander, T. Cost modelling and simulation of last-mile characteristics in an innovative B2C supply chain environment with implications on urban areas and cities. Procedia-Soc. Behav. Sci. 2014, 125, 398-411. 
(57) Browne, M.; Allen, J.; Leonardi, J. Evaluating the use of an urban consolidation centre and electric vehicles in central London. IATSS Res. 2011, 35, 1-6.

(58) van Essen, N. Hoe krijgen we de 'last mile' op de rails? https:// www.logistiek.nl/supply-chain/blog/2013/06/hoe-krijgen-we-de-lastmile-op-de-rails-101132033?vakmedianet-approve-cookies $=1$ \&_ga $=2$. 113928071.1089143942.1534851277-698746241.1534851277, 10 June 2013.

(59) VAL-I-PAC OVERVIEW OF STANDARD INDUSTRIAL PACKAGING WEIGHTS, https://studylib.net/doc/8136333/ overview-of-standard-weights---val-i-pac, date of access: 15 May 2018.

(60) Rajapack, Filla gap paper on a roll; https://www.rajapack.co.uk/ protective-packaging/paper-packaging/filla-gap-paper-roll_ PDT02287.html, Date of access: 10 April 2019.

(61) Alberto, R.; Giulia, S.; Mauro, G.; Cristina, M. A New Paradigm for Packaging Design in Web-based Commerce. Int. J. Eng. Bus. Manage. 2014, 6, 14.

(62) Frey, H. C. Quantitative analysis of uncertainty and variability in environmental policy making. Fellowship Program for Environmental Science and Engineering; American Association for the Advancement of Science: Washington, DC, 1992.

(63) R Core Team R: A language and environment for statistical computing; R Foundation for Statistical Computing: Vienna, Austria, 2017.

(64) Shahmohammadi, S.; Steinmann, Z.; King, H.; Hendrickx, H.; Huijbregts, M. A. J. The influence of consumer behavior on energy, greenhouse gas, and water footprints of showering. J. Ind. Ecol. 2019, 1186.

(65) EPA Optional Emissions from, Commuting; Business Travel and Product Transport: 2008.

(66) UPS Creating Our Tomorrow, Sustainably: 2018 Corporate SUstainability Progress Report. 2019.

(67) Pålsson, H.; Pettersson, F.; Hiselius, L. W. Energy consumption in e-commerce versus conventional trade channels-Insights into packaging, the last mile, unsold products and product returns. $J$. Cleaner Prod. 2017, 164, 765-778.

(68) Mangiaracina, R.; Marchet, G.; Perotti, S.; Tumino, A. A review of the environmental implications of B2C e-commerce: a logistics perspective. Int. J. Phys. Distrib. Logist. Manage. 2015, 45, 565-591.

(69) Borggren, C.; Moberg, Å.; Finnveden, G. Books from an environmental perspective-Part 1: environmental impacts of paper books sold in traditional and internet bookshops. Int. J. Life Cycle Assess. 2011, 16, 138-147.

(70) Wiese, A.; Toporowski, W.; Zielke, S. Transport-related $\mathrm{CO}_{2}$ effects of online and brick-and-mortar shopping: a comparison and sensitivity analysis of clothing retailing. Transp. Res. Part D: Transp. Environ. 2012, 17, 473-477.

(71) Allen, J.; Piecyk, M.; Piotrowska, M. Analysis of online shopping and home delivery in the UK. 2017.

(72) Edwards, J.; McKinnon, A.; Cullinane, S. Comparative carbon auditing of conventional and online retail supply chains: a review of methodological issues. Supply Chain Manage.: Int. J. 2011, 16, 57-63. (73) Amazon https://www.amazon.com/Industrial-Pre-filledBlubonic-Industries-Cushioning/dp/B0191HO1P2?ref = BSellerC\&pf_rd_p=7fb5e9ed-28d6-5380-bc1c-2e5dee106c0a\&pf rd $s=$ merchandised-search-6\&pf $r d t=101 \& p f \quad r d i=$ $8553250011 \& \mathrm{pf}$ rd_m=ATVPDKIKX 0 DER\&pf_rd_r $=$ F5DAS3R8YJYQDZRJ3YD $5 \&$ th=1, Date of access: $15-01-2020$.

(74) Europe, E. Identifying the Top 50 Hot Products in the Fast Moving Consumer Goods Sector in the UK; White Paper. Brussels, Belgium: ECR Europe Shrinkage Group: 2010.

(75) statista Ranking of the most purchased fast moving consumer goods (FMCG) in Germany from 2016 to 2018, 2018.

(76) Kamath, R. Food traceability on blockchain: Walmart's pork and mango pilots with IBM. J. Brit. Blockchain Assoc. 2018, 1, 3712.

(77) Tian, F. An agri-food supply chain traceability system for China based on RFID \& blockchain technology. In 2016 13th international conference on service systems and service management (ICSSSM); 2016; IEEE: 2016; pp 1-6.
(78) Caro, M. P.; Ali, M. S.; Vecchio, M.; Giaffreda, R. In Blockchain-based traceability in Agri-Food supply chain management: A practical implementation, 2018 IoT Vertical and Topical Summit on Agriculture-Tuscany (IOT Tuscany); 2018; IEEE: 2018; pp 1-4.

(79) Barr, A. E-tailers embrace same-day delivery, but US shoppers shrug-survey. https://www.reuters.com/article/etailers-delivery/etailers-embrace-same-day-delivery-but-u-s-shoppers-shrug-surveyidUSL1N0BWD3C20130305, 5 March 2013.

(80) Utter, D. Shop. org asks if business should rush to same-day delivery. http://www.ecommercebytes.com/cab/cab/abn/y13/m04/ i15/s04, 15 April 2013.

(81) Brusch, M.; Stüber, E. Developments and Classifications of Online Shopping Behavior in Germany. Int. J. Cyber Soc. Educ. 2014, 7, 147-156.

(82) Hiselius, L. W.; Rosqvist, L. S.; Clark, A. E-shopping and changed transport behavior. In European Transport Conference 2012; Association for European Transport (AET); Transportation Research Board, 2012; 2012. 